\title{
THE ENERGY CROSSROADS
}

\section{Strategies for sustainable energy development}

\section{CARLOS HidALGO}

Energy is the blood that moves today's society and is one of the factors that has decisively contributed to improving humanity's quality of life. The energy needs of the world's population are expected to double by 2050 and so, considering that available fossil fuels are becoming exhausted, as well as their negative environmental impact, new strategies are needed for sustainable development. This paper addresses the potential challenges and opportunities in the development of global energy systems, emphasising how deeply interconnected the energy and climate debates are.

Keywords: energy, climate change, energy transition, sustainable development.

\section{WHAT ARE YOU TALKING ABOUT?}

If we ask any ordinary citizen the meaning of climate change mitigation scenario $450,{ }^{1}$ the most likely answer would be: what's that got to do with me? Not too long ago, scientists were seen as part of a closed society living in ivory towers and spending much of their time in exotic laboratories and academic institutions. Today, they are increasingly committed to sharing their knowledge and opinions with society.

Like air, energy is essential to the existence and development of the human species. In order to satisfy one's biological needs, an average person needs 2,000 kilocalories a day in the form of food. Translated into power units, this amounts to about $100 \mathrm{~W}$; in other words, in terms of biological consumption, we are the equivalent of a permanently lit $100 \mathrm{~W}$ bulb. $^{2}$ For context, the average European citizen uses approximately $4 \mathrm{~kW}$ per day, which is equivalent to having our European standard of living supported by 40 «slaves» in terms of energy units. However, access

\footnotetext{
1 This scenario refers to the limitation of the carbon dioxide $\left(\mathrm{CO}_{2}\right)$ concentration in the atmosphere to 450 parts per million (ppm).

2 A watt (W) is the unit of power equivalent to 1 joule per second. A joule (J) is a unit of energy in the metric system approximately equivalent to the energy we spend to lift a small apple one metre in height. All human activity and industries require around 500 exajoules $\left(10^{18} \mathrm{~J}\right)$ per year.
}

to energy sources is far from uniform on a planetary scale; while it reaches $10 \mathrm{~kW}$ per capita (over 100 energy slaves) in the USA, consumption in countries like Bangladesh is as low as $0.3 \mathrm{~kW}$. Currently, about 1.5 billion people do not have access to electricity and about 3 billion people use biomass for household needs.

Energy is one of the essential factors that has contributed to the progress and improvement of humanity's quality of life. With energy needs doubling by 2050 and fossil fuels being progressively exhausted, there is an urgent need to develop massive, environmentally sustainable, and socially acceptable sources of energy. This increase in energy demand is a consequence of the combined effect of an increased population and per capita energy consumption in developing countries. We are therefore at an energy impasse where we must promote an energy model that frees us from its environmental impacts.

There are no magic solutions to the intricate energy challenge which humanity faces. All the currently operational options remain necessary, although their availability depends on the environmental and technological circumstances of the different regions of the planet. In the following 
sections, the reader will find some clues which may help us to answer questions related to the energy impasse in which we now find ourselves.

\section{ENERGY SOURCES: THERE IS NO ROSE WITHOUT A THORN}

Science commences when someone poses a general question and attempts to answer it through methodical investigation which includes and combines experimentation and logical argumentation. The scientific method generates knowledge about the functioning of the world in its broadest sense and, therefore, it holds the power to predict nature's behaviour. The practical advantage are corollaries which can be applied from medicine to the development of energy sources.

The search for energy sources dates back to the dawn of humankind. The mastery of fire and agriculture, the use of energy derived from water and wind, and the development of alloys for the construction of tools represented great advances for humanity. The development of steam engines in the second half of the eighteenth century made it possible to transform any type of combustive reaction into mechanical movement and ushered in the industrial revolution. The use of electromagnetism and its applications, among which the first use of electricity stands out, followed during the nineteenth century. Nuclear energy and material physics prompted new energy sources in the twentieth century, and the intensive use of electricity multiplied the applications of energy for new information and communication technologies.

The result is that the energy needs of the average human being have multiplied a hundredfold over the course of history, and advances in the search for energy sources have led to radical changes in our society. But, as the saying goes, there is no rose without a thorn (Table 1). The generation and consumption of energy impact the environment at every stage, from extraction to use, and the effects on climate change are the most concerning threat. Climate change is linked to an increase in the proportion of so-called greenhouse gases in the atmosphere. The most significant among these is carbon dioxide $\left(\mathrm{CO}_{2}\right)$ and its emission is largely the result of burning fossil fuels (coal, oil, and natural gas) as energy sources. Thus, the energy transition requires moving away from the current system towards the promotion of an energy system that does not depend predominantly on fossil sources, as illustrated in Figure 1 (International Energy Agency [IEA], 2017).

Organic matter absorbs energy from the sun through the process of photosynthesis, which allows carbon to be absorbed from carbon dioxide and oxygen to be returned to the atmosphere; subsequently, through a geological-scale transformation period (millions of years), it gives rise to non-renewable fossil fuels (so-called because

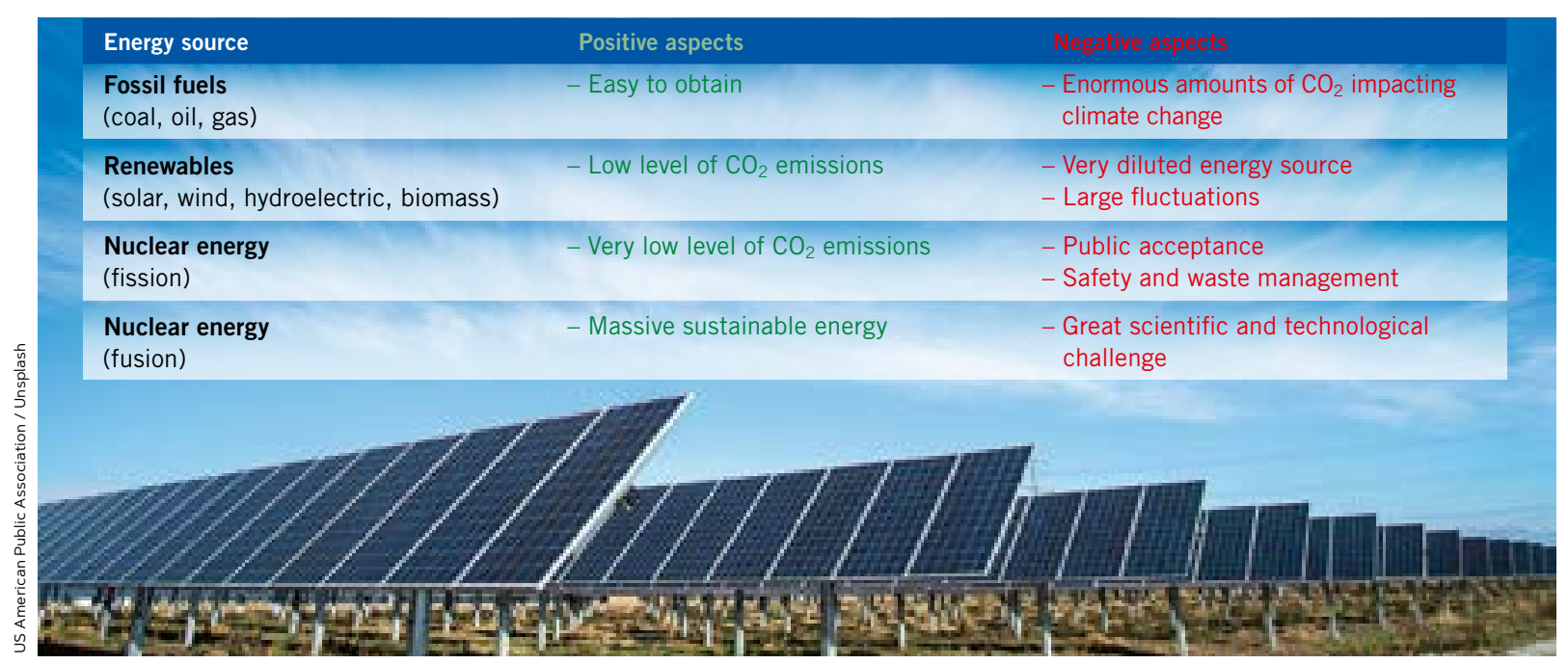

Table 1. Positive and negative aspects of different sources of energy. Energy is one of the essential factors contributing to the progress and improvement of humanity's quality of life, but every step of its generation and consumption has an impact on the environment. 
the timescale of their consumption is much shorter than that of their formation). The data show that our increase in energy needs has not been accompanied by the necessary reduction in fossil fuel use, which represented more than $80 \%$ of the primary energy consumed globally in 2015 .

The debate about the connection between energy sources and climate change has profound political and ethical consequences: if we accept that there is no development without energy, then perhaps access to energy should be included in the Universal Declaration of Human Rights. Given that it is not possible to extend the energy consumption model of developed countries to non-developed countries, what responsibility do the former have in the development model of the latter? (IEA, 2015).

We are facing an energy transition phase with new global forces such as climate change and globalisation. In fact, we need a society with critical knowledge that understands the enormous amount of (fossil fuel-based) energy that we need to replace compared to previous transitions. The search for energy is a global project and new energy strategies require technologies for energy production, transformation, distribution, and saving that favour innovation without endangering the reliability of the energy supply.

\section{FOSSIL FUELS: IS A GLOBAL $+1^{\circ} \mathrm{C}$ INCREASE IN TEMPERATURE REALLY SERIOUS?}

Figure 2 shows the chronological evolution of the Upsala and Arapaho glaciers, located respectively in the Patagonian Andes (Argentina) and in Colorado (USA). Both glaciers are in clear recession, which could be evidence of climatic and geological cycles or of global warming. In this sense, reports by the Intergovernmental Panel on Climate Change (IPCC) conclude that, with a high probability, the increase in the planet's temperature over the twentieth and twentyfirst centuries is a consequence of the increase in the concentration of anthropogenic greenhouse gases (IEA, 2015; IPCC, 2014).

The United Nations Climate Change Conference held in Paris in 2015 marked an important milestone towards a binding global agreement on climate and sustainable energy sources. The agreement sought to limit global emissions so that the temperature of the planet does not exceed a two degrees Celsius difference with respect to pre-industrial temperatures. Considering that the increase is now already in the range of $1^{\circ} \mathrm{C}$, how do we know if a one-degree increase is too much or too little for a favourable

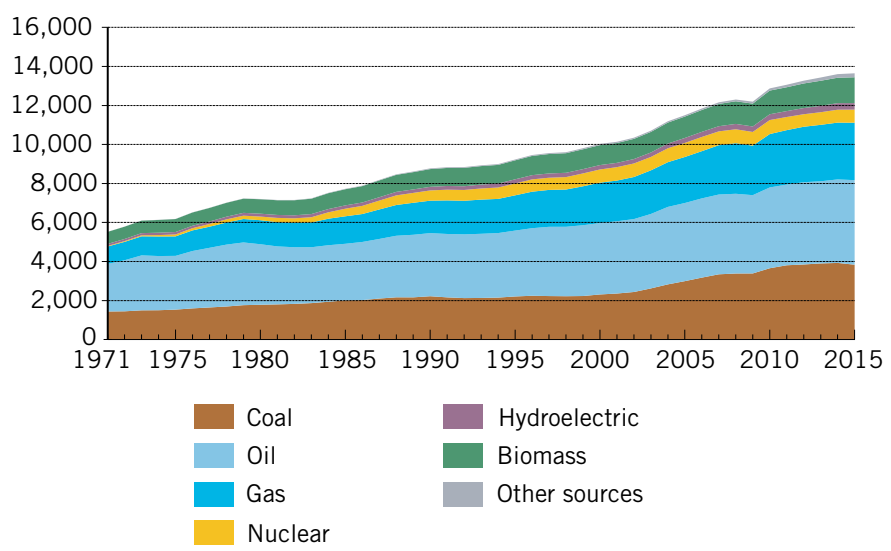

Figure 1. Historical evolution of primary energy consumption over the past few decades. As shown, the energy system depends predominantly on fossil energy sources: coal, oil, and natural gas. SOURCE: International Energy Agency

climate evolution? Readers should draw their own conclusions from the images shown in Figure 2.

At this point, some very important questions arise regarding the cost-benefit balance from both an economic and a social point of view: what is the cost of transforming the current energy system to avoid warming beyond two degrees? What benefits would this strategy provide? The answer to these questions requires a very complex analysis of the dynamic interactions between economy, energy, and climate. Finally, the essential question: where will we end up if we do not change the direction of global energy trends? In democratic societies, citizens will have to decide the level of risk they are willing to accept on behalf of future generations (Alonso Garrido, 2012).

The pending challenges in the transformation of energies based on fossil fuels include several factors. On the one hand, the development of strategies for the reduction of emissions from fossil fuel plants; on the other, the implementation of strategies to capture $\mathrm{CO}_{2}$ emissions and improve energy efficiency.

\section{RENEWABLE ENERGY: NATURE'S GIFT}

Renewable energy is energy obtained from virtually inexhaustible natural sources, either because of the immense amount of energy they contain or because they can regenerate naturally. Some of the most important renewable energies are solar energy (which takes advantage of the sun's electromagnetic radiation) and wind energy (Figure 3). Others are more limited in importance, or are potentially important on a local scale, like hydroelectric energy (which uses the potential and kinetic energy of water currents) and biomass (which uses organic matter) (MacKay, 2009). 
A simple estimate of orders of magnitude is enough to make us aware of the enormous amount of energy we receive from our star, the Sun. From the temperature of the Sun's surface (about 6,000 K), its distance from the Earth (1AU [Astronomical Unit] $\approx 150$ million $\mathrm{km}$ ) and our planet's radius $(6,000 \mathrm{~km})$ we can calculate that the energy reaching the Earth's atmosphere is about $5 \times 10^{24} \mathrm{~J}$ per year. This value is 10,000 times higher than the annual global energy consumption (around $5 \times 10^{20} \mathrm{~J}$ ) (Bret, 2014). Wind energy also originates in the Sun, because wind is produced by the difference in temperature between the different layers of air in the atmosphere; in turn, wind energy can be captured by wind turbines.

What size must a solar farm be to supply enough energy to meet annual global needs? Based on the current efficiency of solar panels (around 30\%) and the solar energy available on the Earth's surface (around $240 \mathrm{~W} / \mathrm{m}^{2}$ ), the area required for the solar farm would be about a million $\mathrm{km}^{2}$; i.e., twice the surface area of Spain (Cifarelli, Wagner, \& Wiersma, 2013).

Because the sun can only produce solar energy (photovoltaic or condensation) during the daytime and because of the erratic nature of wind, solar, and wind energy sources are intrinsically intermittent. The problem of integrating a variable electricity supply into the distribution grid is that it requires energy storage systems and non-renewable energy backup sources.

In this sense, the pending challenges in this field are the development of storage systems for renewable energies (hydrogen, hydrocarbons, chemical storage, hydraulic energy, etc.) and the optimisation of intelligent distribution networks.

\section{NUCLEAR FISSION ENERGY: GREEN ENERGY AND SOCIAL ACCEPTABILITY}

Table 2 compares the efficiency of different energies as well as the typical temperatures at which the process takes place. The energy efficiency of nuclear energies (fusion and fission) is very high, which makes them particularly attractive.

Since the beginning of the nuclear fission era, around 400 nuclear fission reactors have been built and the number of serious accidents has been very small, although their social impact has been very high (e.g., Chernobyl or Fukushima) (Muraoka, Wagner, Yamagata, \& Donné, 2016). The international
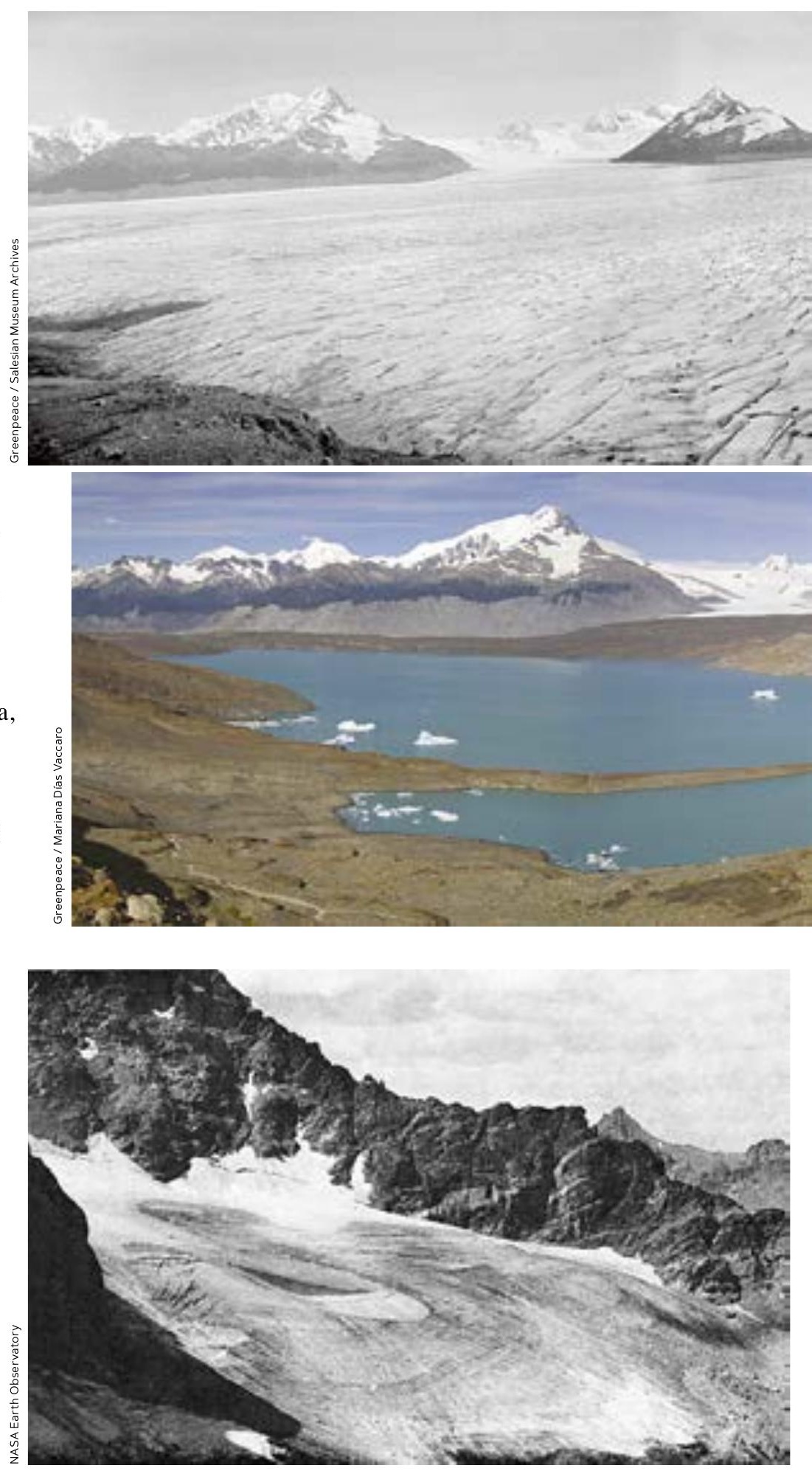

Figure 2. In the two pictures above, the Upsala glacier, located in the Patagonian Andes (Argentina) photographed in 1928 (black and white) and 2004 (colour). Below, the Arapaho glacier in Colorado (USA) photographed in 1898 (left) and 2003 (right). As can be observed, both glaciers are in clear recession. 

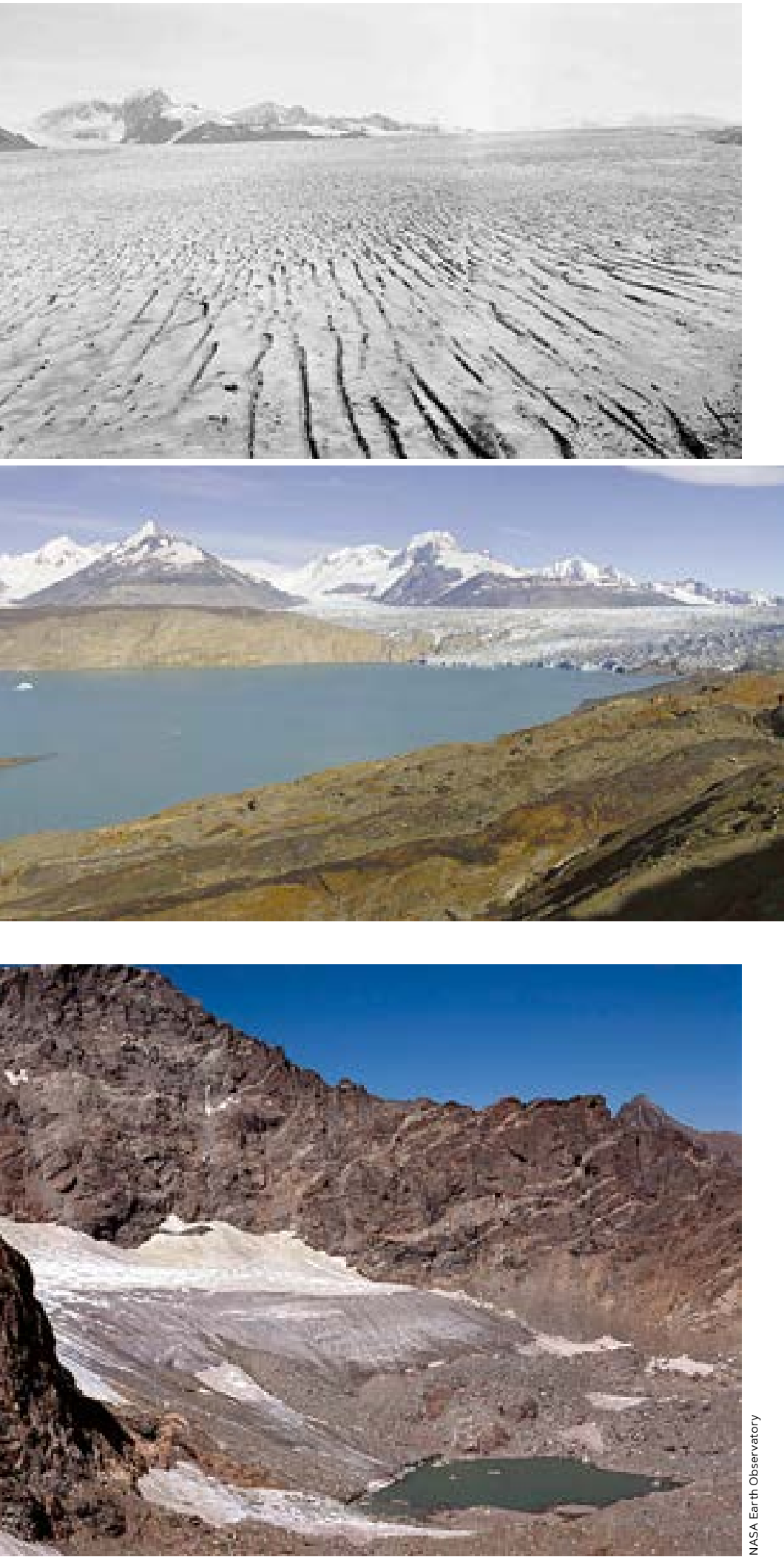

community should encourage greater convergence of nuclear safety approaches, considering technical processes (with an extremely low level of risk) intertwined with a safety culture and human factors.

Faced with the challenges posed by nuclear energy, we can ask ourselves some questions about the technological processes and about the social acceptability of this energy source. Is it technically feasible to process nuclear waste with acceptable disposal and storage criteria? Can environmental emissions and waste disposal be managed to meet society's expectations?

\section{NUCLEAR FUSION ENERGY: A SCIENTIFIC AND TECHNOLOGICAL CHALLENGE}

The energy fuelling the sun and stars is released via fusion reactions (Figure 4). For fusion to occur, the reacting nuclei must overcome electrostatic repulsion and get close enough to each other to allow the attractive nuclear force to come into play. The international scientific community is working on different options (inertial and magnetic confinement) developed to different degrees, geared towards creating tools for harnessing fusion energy in a practical way. In the case of the strategy based on magnetic confinement, the reacting nuclei must be heated to temperatures 15 times higher than that of the centre of the Sun (estimated at 15 million degrees) and must be thermally isolated from the surrounding environment using an intense magnetic field (around 5-7 T, ${ }^{3}$ i.e., 100,000 times the Earth's magnetic field).

At these extreme temperatures, matter consists of a highly ionized gas called plasma. The development of viable nuclear fusion energy requires solutions to several major scientific and technological problems (Romanelli, 2012).

The main outstanding challenges in nuclear fusion include the integration and optimisation of physics and technology criteria. From the point of view of plasma physics, ignited plasma must be efficiently confined; that is, plasma that is reactive enough to produce substantially more energy than the energy used in its generation process. From a technological point of view, self-sufficiency in the generation of tritium must be proven and materials resistant to the intense and highly energetic neutron fluxes of nuclear fusion must be developed.

\footnotetext{
A tesla (T) is the unit of the magnetic field strength. It owes its name to the brilliant scientist Nikola Tesla, who, as an advocate of alternating current, waged an epic war of currents with Edison, who favoured direct current.
} 



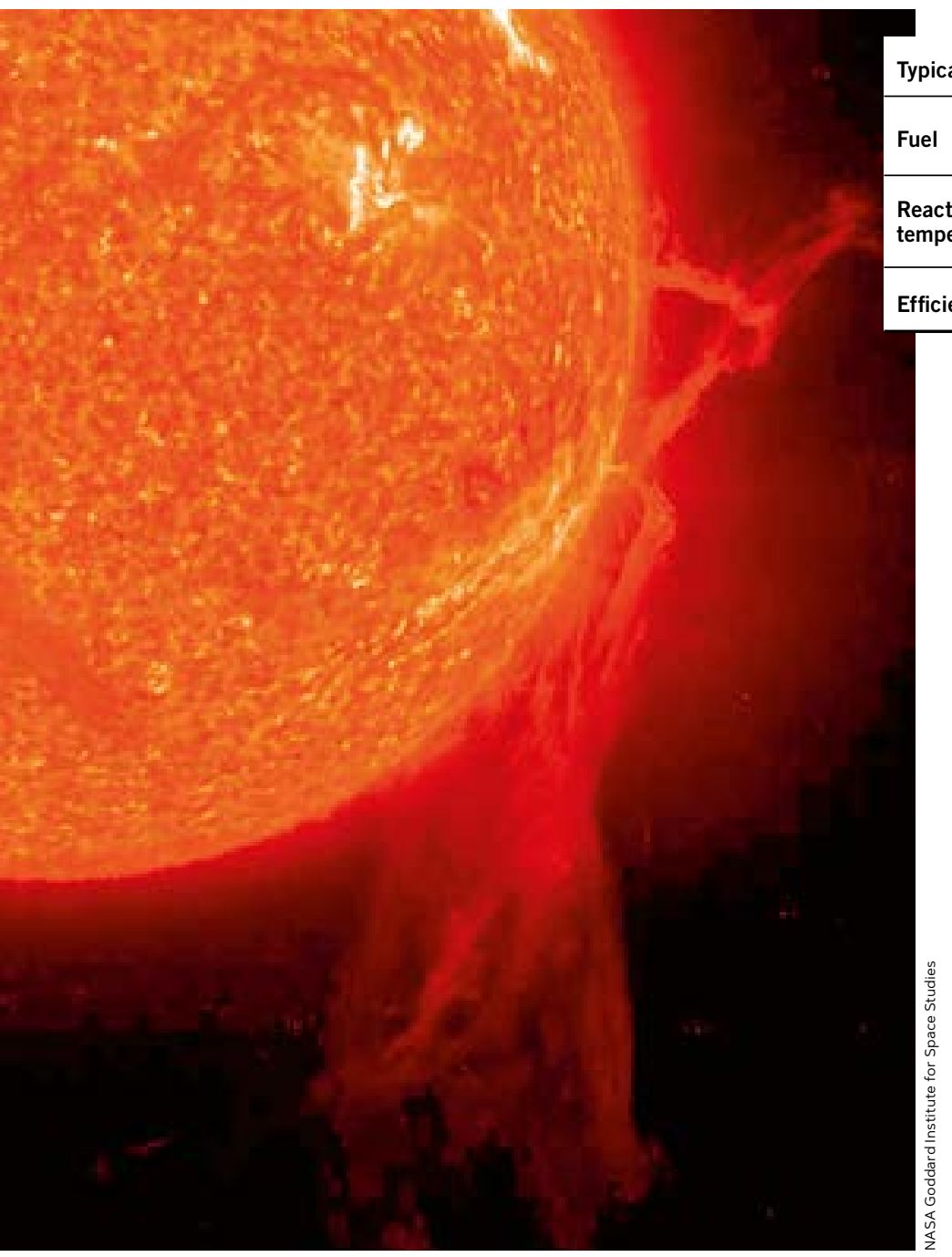

Figure 4. What makes humans truly unique is our ability to imagine and shape the future through a combination of science and technology. An example of this is our desire to control the energy driving the universe: nuclear fusion. Fusion reactions are the ones that release the energy that fuels the Sun and every other star.

\section{«We must be realistic: the need for new energy generation, transformation, and storage strategies is a colossal challenge»}

Chemistry

Nuclear fission

Nuclear fusion

\begin{tabular}{lccc} 
Typical reaction & $\mathrm{C}+\mathrm{O}_{2} \rightarrow \mathrm{CO}_{2}$ & $\mathrm{n}+\mathrm{U}^{235} \rightarrow \mathrm{Ba}^{143}+\mathrm{Kr}^{91}+2 \mathrm{n}$ & $\mathrm{H}^{2}+\mathrm{H}^{3} \rightarrow \mathrm{He}^{4}+\mathrm{n}$ \\
\hline Fuel & Coal & $\begin{array}{c}\text { Uranium oxide } \\
{\left[3 \% \mathrm{U}^{235}+97 \% \mathrm{U}^{238}\right]}\end{array}$ & $\begin{array}{c}\text { Deuterium } \\
\text { and tritium }\end{array}$ \\
\hline $\begin{array}{l}\text { Reaction } \\
\text { temperature }(\mathrm{K})\end{array}$ & 700 & 1,000 & $100,000,000$ \\
\hline Efficiency $(\mathrm{J} / \mathrm{kg})$ & $3 \times 10^{7}$ & $2 \times 10^{12}$ & $3 \times 10^{14}$ \\
\hline
\end{tabular}

Table 2. Efficiency and reaction temperature of chemical and nuclear energy sources. During nuclear fission reactions, heavy elements produce lighter elements. Conversely, in the process of nuclear fusion, light elements are combined to produce heavy elements. The sum of the masses of the reagents after a nuclear fission or fusion reaction is lower than the sum before the reaction in a $\Delta \mathrm{m}$ quantity which we call a mass defect. According to the theory of relativity, nuclear fusion releases an amount of energy $E=\Delta m c^{2}$, where $c$ is the speed of light. The extremely high value of $c^{2}\left(c^{2}=90,000,000,000,000,000 \mathrm{~m}^{2}\right)$ $\mathrm{s}^{2}$ ) explains the enormous efficiency of nuclear energy compared to energies of chemical origin. While in the case of chemical and nuclear fission energies the reaction temperatures are easily accessible (ranging from 700 to $1,000 \mathrm{~K}$ ), in the case of nuclear fusion, temperatures of hundreds of millions of degrees are required.

\section{REFERENCES}

Alonso Garrido, A. (2012). La energía como elemento esencial de desarrollo. Consecuencias de un modelo energético insostenible. Madrid: Asociación de Ingenieros Industriales de Madrid. Retrieved from http://aiim.es/ wp-content/uploads/2016/06/La-energ\%C3\%ADa-como-elementoesencial-de-desarrolo..pdf

Bret, A. (2014). The energy-climate continuum: Lessons from basic science and history. Cham/Heidelberg/New York/Dordrecht/London: Springer. doi: 10.1007/978-3-319-07920-2

Cifarelli, L., Wagner, F., \& Wiersma, D. S. (2013). New strategies for energy generation, conversion and storage. Lecture notes Joint EPS-SIF International School on Energy, Varenna 2012. Bologna: SIF.

International Energy Agency. (2015). Energy and climate change. Paris: OECD/ IEA. Retrieved from http://www.iea.org/publications/

freepublications/publication/WEO2015SpecialReportonEnergyand ClimateChange.pdf

International Energy Agency. (2017). Key world energy statistics. Paris: IEA. Retrieved from http://www.iea.org

IPCC. (2014). Summary for policymakers. In O. Edenhofer et al. (Eds.), Climate change 2014: Mitigation of climate change. Working group III contribution of to the Fifth Assessment Report of the Intergovernmental Panel on Climate Change. Cambridge, RU and New York, NY, EUA: Cambridge University Press.

MacKay, D. J. C. (2009). Sustainable energy - Without the hot air. Cambridge: UIT Cambridge.

Muraoka, K., Wagner, F., Yamagata, Y., \& Donné, A. J. H. (2016). Short- and long-range energy strategies for Japan and the world after the Fukushima nuclear accident. Journal of Instrumentation, 11, C01082 . doi: 10.1088/17480221/11/01/C01082

Romanelli, F. (Ed.). (2012). Fusion electricity. A roadmap to the realisation of fusion energy. European Fusion Development Agreement. Retrieved from https://www.euro-fusion.org/fileadmin/user_upload/EUROfusion/ Documents/Roadmap.pdf

CARLOS HIDALGO. Researcher at the National Fusion Laboratory of the Centre for Energy, Environmental, and Technological Research (CIEMAT, Spain), where he currently leads the Experimental Physics Division. His research work focuses on the study of high-temperature plasmas. He has worked in different international laboratories in Europe, the USA, and Japan and has published numerous papers in international journals about solid state physics and nuclear fusion plasma physics. He complements his research activity with teaching. $\square$ carlos.hidalgo@ciemat.es 